\title{
Appropriation of information in data visualization
}

\author{
Antonio Lucio Barizon Filho, Pedro Henrique Cremonez Rosa
}

appropriation of

information, information

visualization,

information

representation
The study seeks to understand which elements related to the process of appropriation of information are facilitated and supported by data visualization. Based on the understanding that appropriation of information encompasses the transmission of information and its learning by the user, the visual representation of the data, through graphic resources, assists in this process by synthesizing the information content in a clear manner, thus reducing abstractions. The study is based on a bibliographic survey of an explanatory character, trying to bring reflections on the importance of visualizing data in the process of appropriation of information.

\section{Introduction}

The production of information and knowledge has always gone hand in hand with humanity's development. Nowadays, with the shift from the physical support of documents to digital support, the growth in the information volume available has increased exponentially. According to Vopson (2020), 90\% of all existing virtual content was created in the last decade only. The excess of information, resulted from this growth in the sources that produce information and knowledge, requires more efficient ways of organizing and representing information. Inserted in this reality in which informational consumption is put under the contemporary perspective of speed and practicality, informational flows are now optimized in their form and content for the same purpose, to meet the users' need.

The informational volume, manifested as large capacities of texts, does not meet the needs of fast and immediate information consumption that users demand. In a society guided by visuality, data visualization is a powerful tool for representation of data and information, previously oriented as texts and numbers, to shapes and formats with synthetic and analytical power.

Through visualization, the user starts to acquire large quantities of knowledge summarized in an imagery context. Here, visualization is understood as ways of accessing information from techniques that compensate content through graphic resources and visual attributes, such as point, line, shape, size, brightness, texture, color, orientation and positioning. According to Tufte (1998), visioning works on the combination of words, numbers, images and art using the forms, layout, composition, color, typography, management and 
understanding of data and information as instruments. Its quality is the result of knowledge about the visual principles that tell us how and where to put the right element in the right place.

In view of facilitating characters that visual representations may have, this study seeks to go beyond the characteristics and aesthetics appeal of visualizations to understand the cognitive process behind the visual graphic language and what are the possible advantages that exist in this type of manifestation for appropriation of information.

The present work has a theoretical background that reflects on which factors related to the appropriation of information processes are facilitated through visualization. The objective of the study, at first, was to identify and describe the principles of appropriation of information, followed by a review of the characteristics of data visualization. From the explanatory research, it was possible to start from a deductive process aiming to compare the principles of the appropriation of information to the forms of data visualization and techniques that corroborate the appropriation and how informational design practices can enhance the process. For this, bibliographic research was developed on the appropriation of information, as well as data visualization and information design, as a theoretical foundation and substance for the creation of correlations between the areas of study.

\section{Appropriation of information}

The process of appropriation of information involves the moment of information being transferred (Barreto, 1999) in which the user/ reader grasps the information, as the sum of the stages in which the individual seeks, uses and effectively supplies his informational needs (Carvalho, 2010). In this course, the reader tends to reflect, condense and seek concepts related to the information accessed. From this process, the appropriation of information occurs, since the user is able to fully absorb new informational content. For Robredo (2003), the transmission of knowledge starts from codifications of knowledge made by the individual, from his previous repertoire, enabling the learning of new informational content.

For Batista (2018) the concept of appropriation can be understood as a synonym for adaptation, assimilation, incorporation, interiorization and transmission and from different perspectives: appropriation as subjectification, resignification, identification, symbolic representation and construction of meaning. In this way, the author understands the process of appropriation

in which the subject "makes his" an object of the world, adjusting it, molding to himself, acting affirmatively in the processes of negotiation with signs and culture. In this process, the object, material or not, undergoes a space-time displacement promoted by the subject, which can alter or confirm the meaning given by its original environment, 
that is, it can re-signify the world that arrives to it, from its perceptions, their expectations and interests of and by activities (Batista, 2014, p. 57, our translation).

The perspective that the appropriation of information relates to the actions of understanding the content and its absorption by the user supports the importance of the cognition involved in the process. The information previously contained in a document starts to transition in the individual's logical perception, which refreshes his previous conceptions, reinforcing the view proposed by Brookes (1980) that the contact with the new information provides transformations in the individual's mental structures and knowledge, by means of transfer.

In these conditions of knowledge transfer in which users take on new information, Borges (2018) studies about appropriation of information within the research developed by Information Science, identifying them as embryonic. Searching to dimensionalize, then, the process of appropriation of information, Borges (2018) retakes the seven directives of thought, by Edgar Morin, in the work Une tête bien faite: Repenser la réforme, réformer la pensée, understanding the process as multifaceted. The author assumes that the appropriation of information by the individual involves the individual's ability to materialize the information, that can be divided into seven categories: systemic appropriation, holographic appropriation, retroactive appropriation, recursive appropriation, regenerative appropriation, dialogic appropriation, interdependent appropriation.

\footnotetext{
Reflecting on the process of appropriation and materialization of information, it can be thought that the process of appropriation transforms the abstract and non-existent into organized matter, in the same way it transforms false information into truths to balance the understanding of the world that the subject has according to his reality and momentary facts (Borges, 2018, p. 146).
}

Systemic appropriation involves the appropriation of information through previous appropriations. In this way, exposed information can be understood and appropriated from previous knowledge. In the process of systemic appropriation, "the materialized information of other previously appropriated information" (Borges, 2018, p. 139-140) results in the understanding of the information as a whole, not in a reductionist way, but in an integrative way.

Holographic appropriation is understood as the fact that information, to be suitably appropriated by the individual, implies that he has already made previous appropriations of other information in the course of life, returning to them for new appropriations. In this way, the understanding of the parts is given from a whole, just as the whole can be understood from its parts.

In retroactive appropriation, there is the appropriation of information through the duality between organizing and disorganizing 
information, for example. To understand new information, previous ones had to be disorganized and reorganized. Future information will generate this new disorder and ordering, retroactively. In this way, retroactive appropriation is closely linked to recursive appropriation. In the second, information is a product and producer of the process itself, going beyond information that generates information, but for appropriation processes it generates new processes.

Regenerative appropriation implies that information appropriation processes are constant, self-producing and unfinished. In this category, cycles of appropriation of information are permeated by informational manifestations or simple data. This dialogical nature of appropriation reflects many of the categories mentioned above, in which moments information does not exist as material, but as a potential under construction and, other times, there is the physical manifestation of that same potential, characterizing the category of dialogical appropriation.

Finally, the interdependent appropriation comprises the fact that knowledge is not indigenous. The information is appropriate, reconstructed from other appropriations and allows for future appropriations. This category encompasses all others because it deals with the process of appropriating information not as steps, but as a natural movement of interaction between the individual and the information. The visual representation of textual information, for example, guarantees a construction of new knowledge, by what has already been explored textually, based on the image and its perceptual potential within the document.

\section{Data visualization}

For Zhang (2007), visualization is the transformation of data, information and knowledge into visual representations that aims to facilitate the performance of tasks such as data analysis, explanation and exploration of information, pattern detection, trend forecasting, rhythm discovery and much more. Visualization, however, is not just a matter of visual and graphic decision making. In its creation process, it is necessary to extract evident attributes and establish connections between the represented objects, it is necessary to organize the information and understand which properties are best represented in a visual way and how these properties can be represented and organized visually to clarify and highlight the relationships between the data.

Supported by the definition that visualization is the activity of forming a mental model of something, Spence (2001) states that visualization is, by meaning, a human activity, being, therefore, independent of computing, despite the fact that the practice can be improved immensely with computer support. In order to reinforce his argument, the author presents a series of examples of visualizations with historical importance developed before computation, such as 
Florence Nightingale's "Rose diagram" of 1858, John Snow's “cholera map" of 1855, Charles Minard's 1869 Napoleon March to Moscow and Harry Beck's 1931 London Underground map.

Ware (2019), however, explains that, although the term visualization is related to the construction of a mental image, currently the term is more related to the graphic representation of data or concepts. For the author, the term went from being an internal construct of the mind to an external artifact to support decision-making. Ware (2019) approaches the computer as a tool to produce visualizations, that is, before building algorithms to create the images, it is necessary to determine the best way to visualize the data for a specific task and emphasizes that the critical question is precisely to understand the best way to turn them into something that people can understand.

The increase in interest of visualizations, and consequently studies in the area, accompanied the substantial growth in the amount of data produced, stored and shared, especially from the second half of the twentieth century. For Colonna (1994, apud Zhang, 2007), data visualizations naturally benefit from the fact that vision is the most developed human sense to receive, recognize and understand the environment.

Thus, information overload is one of the main concerns in representing results obtained through information retrieval mechanisms. One approach to circumvent the difficulties of selecting the relevant information from the search results is to use information visualization techniques through which the user obtains a visual representation that, if on the one hand abstracts details from the set of information, on the other provides an organization of this set according to some criterion. (Freitas et al., 2001, p. 144)

According to Zhang (2007), most of the concepts established by human beings with the environment are made from visual perception, specifically by the various patterns formed by graphic entities such as point, line, shape, color, dimension, position and displacement. These patterns, according to the author, reveal information, encapsulate knowledge and elucidate data properties. Visual representation, therefore, increases cognitive abilities by increasing available resources, improving pattern recognition and reducing search effort, which helps readers to understand, learn and remember information.

Aguilar et al. (2017) explains that the data, by itself, has no meaning and does not allow decision making or defines future actions. Data are the basis however, alone are not enough to establish the information and communication process. The visual representation of data allows the creation of information, which can be transformed into knowledge. As actions, data visualization allows to categorize, calculate, quantify, and collect information. The processing, organization of a significant form and presentation of the data in an appropriate format, when communicating and representing its 
surroundings, give meaning and produce the information effect. "Information is a meaningful piece of data that has now been interpreted. In this way, it allows an operational manager to decide on what measures should be taken." (p. 51, 2017).

One of the great benefits of visualization, according to Ware (2019) is the large amount of information that can be quickly interpreted if properly represented. Among the advantages of visualization to organize and represent, Ware highlights the possibility of immediately understanding the most important information of gigantic amounts of data, the perception of properties and patterns that would be imperceptible in other forms of representation and the possibility of identifying problems in how the data was collected. In addition, visualization allows a more general understanding of the information and facilitates the formation of hypotheses, which can motivate further research.

\section{Visualization and appropriation of information}

According to Catania (1999), readers and listeners are not passive, but behave verbally during readings and speeches in which they think, reason, articulate content and infer about the subject covered. By learning something, through the process of appropriation in this case, the reader is able to understand the content covered by means of semantic coding. The user, playing the role of reader, tends to retain new content based on semantic structures or visual imagination stimulated by the text. For example: if a user is faced with a visual stimulus and from it creates semantic encodings, such as analogies and contextual metaphors that help understanding the content, the likelihood of remembering the same content increases. In this way, "imagining an object, for example, must have something in common with seeing the object" (Catania, 1999, p. 355). Visualizing data and information, in the same way, implies their mental representation, that is, the appropriation of information.

Skinner (2003) already postulated the importance of visual perception of certain contents. In a practical example, the author proposes a logical exercise with a cube of six faces painted red. When applying horizontal and vertical cuts to the cube, generating 27 identical smaller cubes, how easy would it be to ration the number of smaller cubes that had three, two, one or no red faces? As a proposal, the use of visual examples, even simplified sketches, facilitate the solution of a certain issue. Consequently, when large volumes of data can be summarized in visual exemplifications, there is a greater ease in understanding by semantic coding and learning of the content. In this way, semantic coding, which involves understanding contextual content, linked to visual stimuli of representation of this same content, allows a greater number of logical processes that converge to the same end, the understanding of certain information, 
through its visualization. Starting from the seven categories raised by Borges (2018), what are the characteristics and considerations in relation to the visualization of data that influence the appropriation of information?

The starting point of the relationship starts from the author's thought, that "reflecting the process of appropriation and materialization of information, one can think that the process of appropriation transforms the abstract and non-existent into organized matter [...]" (Borges, 2018, p. 146). Visualization, as a representation of data, is linked to the concept of substitution because, according to Alvarenga (2003, apud Lima; Alvares, 2012, p. 15) “[...] when we represent, we create a relationship between what is presented and the sign, in an act of substitution using symbolic elements, such as: words, numbers, diagrams, figures, etc". Therefore, visualization can be seen from the same reflection as Borges (2018) in relation to appropriation: as a process that organizes and represents information from the reduction of its abstraction and substitution.

For Moles (1974, p. 97) "the degree of abstraction (or, equally, of iconicity), is consequently an important dimension of the universe of images, linked to the property that an image has to reflect the real world, to be a reduction of this.". Moles' scale of iconicity or abstraction is one of the best known and most used in the graphic area and proposes a sequence of levels of abstraction divided into 12 degrees that constitute one of the essential characteristics of visual representation. The scale starts from the maximum iconicity, which is the object itself up to the most abstract, the representation of the object by means of words, numbers or mathematical formulas (of arbitrary character and null iconicity). In such a way, it is possible to suppose that a characteristic of the data visualization that enhances the appropriation is the fact that, by reducing the level of abstraction, the visualization decreases the cognitive effort necessary to appropriate the information, since part of the process has already been carried out in the representation.

The amount of information in a visualization and the level of detail or abstraction must be thought according to the content, the format, the objectives, the audience and the media:

A visual should contain the details that are essential in communicating the intended message. Too many details and too much complexity give rise to distracting "interference" and reduce the interest for the content and the impact of the important part of the content in the visual. Thus, we should avoid unnecessary elements in the picture. Too few details or too little complexity makes it impossible to understand the picture. For each picture there is an optimal degree of detail (Pettersson, 2015, p. 140).

Thinking, then, of the seven categories about appropriation of information proposed by Borges (2018), it is possible to create a parallel between the process of appropriation of information and data 
visualization. A textual document presents a lot of information during its writing and reading. When a visual representation is presented, that condenses the data and information described textually, a reader starts to appropriate the information in a systemic way, because when faced with graphic resources that reinforces and resumes previously discussed contents, the knowledge acquired by reading passes on to be incorporated by the visual element itself.

As previously mentioned, data visualization has the principle of reducing abstractions from the text and condensing large volumes of content into a single graphic resource. Thus, when representing synthesized parts of a whole, the appropriation of information tends to have a holographic character, as it retrieves pre-established information in the text and presents it in a summarized manner. In the same way that the image represents the text, the text is represented by the image.

The development of a visualization implies appropriation, selection and organization of data for its representation. Understanding that this appropriation has a systemic and holographic character, that is, it is recurrent and influenced by other information, its selection and organization, consequently, is also influenced in such a way that, as a human manifestation, the entire visualization creation process is permeated by subjective aspects and is therefore subject to biased decisions. This characteristic is present both in the development and in its reading, since visualizations are composed of different elements (such as labels, graphics, images, titles, legends and others) in different graphic languages. Reading each of the parts contributes - and can influence - in the interpretation of the whole, as shown by Kong, Liu and Karahalios (2018), who found out that the title can influence the main message perceived, with readers having opposite conclusions from the same visualization.

Data visualization also allows retroactive and recursive appropriation. A document, for example, that presents a graphic representation of the subject addressed starts from the disorder of the content previously described by the language and organizes it with an image representation. In this new composition, the visualization of data through graphic representation establishes new relationships with the reader / user, generating new appropriations on the subject addressed or even expanding to new knowledge. Likewise, visualization is a way for the user to appropriate information in a regenerating way, as it does not occur in a continuous and dialogical way. Visually represented data is knowledge that can be materialized for the user, and deconstructed at other times, based on new knowledge.

The appropriation of information, therefore, has its interdependent character because it is not an autochthonous process. The reader uses representations to mentally materialize the content covered in the text, generating new interpretations for graphic representations. This creates a repertoire in relation to the individual's informational skills, fostering his theoretical framework for reading new iconographic elements, new visual syntheses and new representations that reduce 
the abstraction of the text. The visualization of data occurs from arbitrary forms and organizations, requiring previous knowledge on the part of the reader to be read and understood, what can be observed in the Pew Research Center survey that shows that only 63\% of American adults can read a scatterplot correctly (Goo, 2015).

In addition to choosing the most appropriate visualization to be used to represent the data, other practices can help the reader to read and understand the visualization. The use of clear and simple labels placed next to the related shape, instead of being in a separate frame, allows the reader to clearly identify what is being represented. Instead of describing the data being represented, the title can indicate the arguments to be made - although a common criticism of this practice is that can make the visualization look biased. Finally, the use of "annotation layers", textual captions that help to place the data in context, highlight the most important facts and clarify possible misinterpretations. Therefore, when reading a graph, the reader is able to appropriate this visual information based on reflections or assumptions previously established (example, Figure 1).

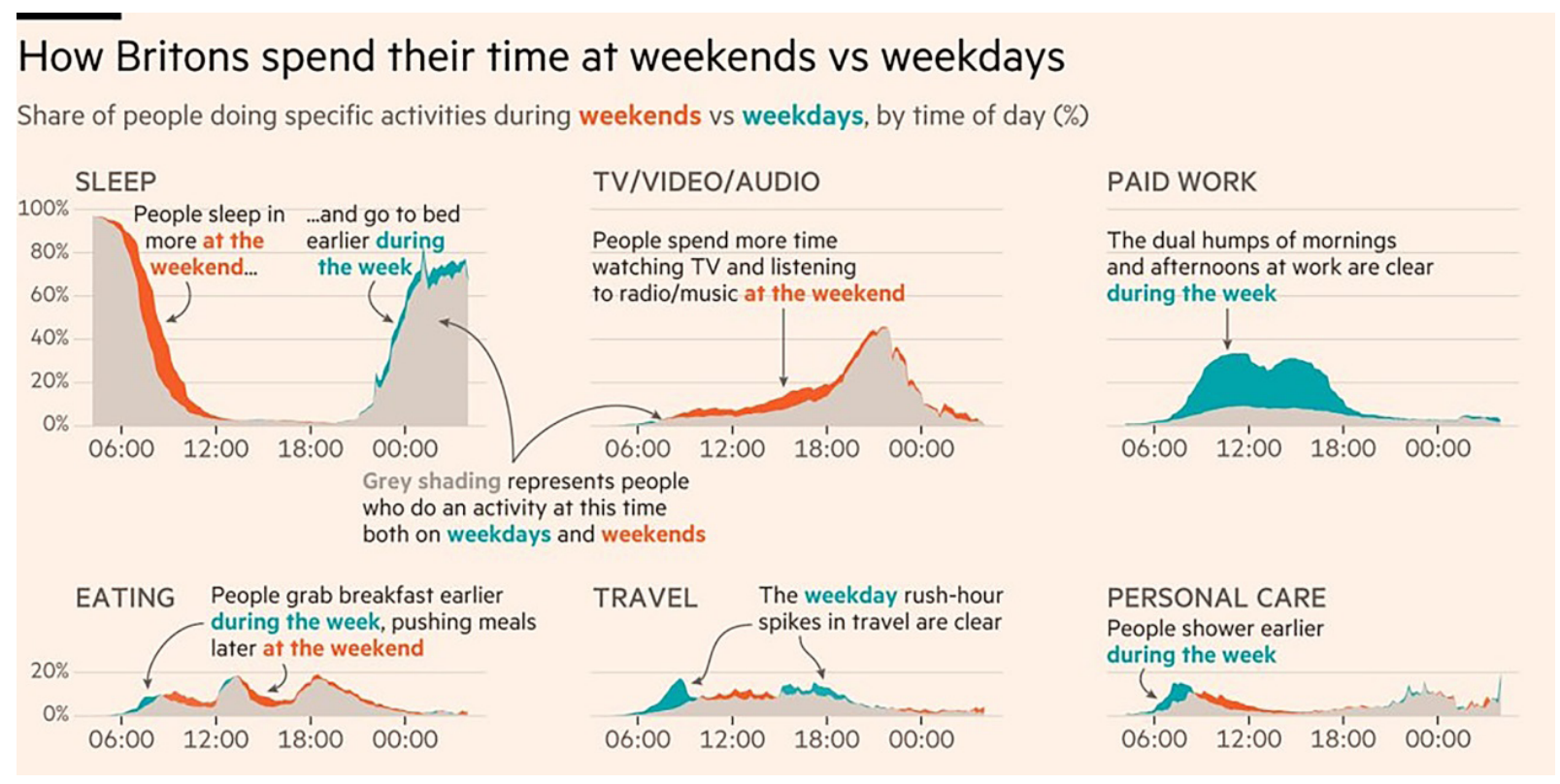

Figure 1 The use of labels, titles and annotation layers to improve read and comprehension. Font: Financial Times (https://www.ft.com/content/085749dc-3cac-11ea-b232-0oof4477fbca)

Visual representations, therefore, are able to summarize data and information to be appropriated in a condensed and synthesized way. In this movement of simplification of representation, the forms of appropriation of information made by the user are mediated, from the moment when the clarity that the graphic resources offer in the process of reducing abstractions and in the mental materialization of the content are stimulated. 


\section{Final considerations}

The objective of the study was to understand, based on the concept of appropriation of information, which are the characteristics of data visualization that enhance the transmission and appropriation of information. Bearing in mind that the appropriation of information process has its centrality in human cognition and in the transformation of thought and knowledge structures, appropriation depends both on the action of transmitting information, on the part of the emitting source and reaching the user's informational need as well as learning the information provided and obtained.

Understanding, therefore, the appropriation of information has its inherent complexity in the very conception of information, being a concept in constant discussion and without an end. As stated by Almeida Júnior (2009), information creates conflicts that enable ways to transform the knowledge of the individual. The appropriation of information, therefore, seeks not to reduce uncertainties but to reconstruct knowledge from the disorganization of previous appropriations, from the destruction of certainties, and the organization of new knowledge.

The categories of appropriation of information proposed by Borges (2018) aim to dimensionalize the process intrinsic to the individual's cognition, seeking to bring practical concepts that describe the relationships that the user may have with the information. It is important to note that the proposed categories, based on their nature, occur simultaneously and concurrently in the process of appropriating the information. Thus, a method of assisting the appropriation of information process comprises creating forms that facilitate the transmission of information and the processing of information by the reader. This facilitation, as seen, can start from visual elements that materialize the knowledge exposed in an organized, simplified and summarized way.

The considerations raised, however, indicate care and reflections to be made in relation to the visualizations. Regarding its creation, representing data requires, among others, a knowledge of the data, visualization techniques, objectives and the reading public. Understanding the data and information is essential not only for its reliable representation, but for the very decision of how it will be represented since different types of organizations and visualizations are necessary to establish relationships and highlight the properties of the data. On the other hand, understanding the complexity of the data and its entire path to representation can provide a more critical reading of the visualization and a questioning of the appropriated information. 


\section{Acknowledgement}

This work was carried out with the support of the Coordination for the Improvement of Higher Education Personnel - Brazil (CAPES) Financing Code 001.

\section{References}

Aguilar, A. G., Pinto, A., Semeler, A., \& Soares, A. P. (2017). Visualização de dados, informação e conhecimento. Florianópolis: Editora UFSC.

Almeida Júnior, O. F. (2009). Mediação da informação e múltiplas linguagens. Tendências da pesquisa brasileira em Ciência da Informação, Brasília, v. 2, n. 1, p. 89-03, jan./dez.

Barreto, A. A. (1999). A oferta e a demanda da informação: condições técnicas, econômicas e políticas. Ciência da informação, v. 28, n. 2, p. 168-168.

Batista, C. L. (2014). Mediação e apropriação da informação pública: a educação fiscal. 2014. 273f. Tese (Doutorado). Programa de Pós-Graduação em Ciência da Informação - Escola de Comunicação e Artes, Universidade de São Paulo, São Paulo. Retrieved from: https://www.teses.usp.br/teses/ disponiveis/27/27151/tde-18052015-160609/pt-br.php.

Batista, C. L. (2018). Os conceitos de apropriação: contribuições à Ciência da Informação. Em Questão. Porto Alegre, Vol. 24, n. 2. p. 210-234.

Borges, E. V. E. (2018). Apropriação da informação: os elementos, o processo e a materialização da informação. 256f. Tese (Doutorado) - Programa de PósGraduação em Ciência da Informação, Universidade Estadual Paulista (Unesp), Marília, 2018. Retrieved from: https://repositorio.unesp.br/ handle/11449/180438.

Brookes, B. C. (1980). The foundations of information science. Part I. Philosophical aspects. Journal of information science, v. 2, n. 3-4, p. 125-133.

Carvalho, A. M. G. (2010). Apropriação da informação: um olhar sobre as políticas públicas sociais de inclusão digital. 169f. 2010. Tese (Doutorado). Programa de Pós-Graduação em Ciência da Informação, Universidade Estadual Paulista (Unesp), Marília. Retrieved from: https://repositorio.unesp.br/ handle/11449/103358.

Catania, A. C. (1999). Aprendizagem: Comportamento, Linguagem e Cognição. Porto Alegre: Artmed.

Freitas, C. M. D. S., Chubachi, O. M., Luzzardi, P. R. G., \& Cava, R. A. (2001). Introdução à visualização de informações. Revista de informática teórica e aplicada. Porto Alegre. Vol. 8, n. 2 p. 143-158.

Goo, S. K. (2015, September 16). The art and science of the scatterplot. Pew Research Center. https://www.pewresearch.org/fact-tank/2015/09/16/ the-art-and-science-of-the-scatterplot/

Kong, H.; Liu, Z.; \& Karahalios, K. (2018). Frames and slants in titles of visualizations on controversial topics. In: Proceedings of the $2018 \mathrm{CHI}$ Conference on Human Factors in Computing Systems. p. 1-12. 
Lima, J. L. O.; \& Alvares, L. (2012). Organização e representação da informação e do conhecimento. Organização da informação e do conhecimento: conceitos, subsídios interdisciplinares e aplicações. São Paulo: B4 Editores. 248: 21-48.

Moles, A. A. (1974). O cartaz. São Paulo: Ed. Perspectiva.

Pettersson, R. (2015). Image design. Institute for infology.

Skinner, B. F. (2003). Ciência e Comportamento humano. São Paulo:

Martins Fontes.

Spence, R. (2001). Information visualization. New York: Addison-Wesley.

Tufte, E. R. (1998). Envisioning information. Connecticut: Graphic Press.

Vopson, M. (2020). The information catastrophe. AIP Advances, v. 10, 2020. Retrieved from: https://aip.scitation.org/doi/10.1063/5.0019941.

Ware, C. (2019). Information visualization: perception for design. Morgan Kaufmann.

Zhang, J. (2007) Visualization for information retrieval. Springer Science \& Business Media.

\section{About the authors}

\section{Antonio Lucio Barizon Filho}

antonio.barizon@uel.br

Universidade Estadual de Londrina, Brasil

Pedro Henrique Cremonez Rosa

pedrocremonez@gmail.com

Universidade Estadual de Londrina, Brasil

Submission date: $3 / 5 / 2021$

Approvement date: 30/9/2021 